\title{
REPUBLICANISMO: UNA ACTUALIZACIÓN COMO TEORÍA DE LOS ESTADOS LIBRES
}

\section{REPUBLICANISM: AN UPDATE AS A THEORY OF FREE STATES}

\section{Giancarlo Garcés Arce}

Universidad Nacional Mayor de San Marcos, Lima, Perú

giancarlo.garces@unmsm.edu.pe

https://orcid.org/0000-0002-8346-7807

Recibido: octubre de 2021

Aceptado: noviembre de 2021

Palabras clave. Republicanismo, independencia, libertad, neorrepublicanismo, dominación.

Keywords: Republicanism, independence, freedom, neo-republicanism, domination.

Resumen: El neorrepublicanismo de Quentin Skinner, Philip Pettit y Maurizio Viroli tiene el mérito de haber recuperado la idea republicana de libertad para abordar críticamente las distintas formas de dominación que permean las sociedades democráticas contemporáneas. No obstante, en un primer apartado, se sostiene que tales propuestas normativas aprovechan insuficientemente los alcances críticos de la libertad republicana, porque únicamente la instrumentalizan para defender las libertades de los individuos, pese a que a los republicanos del pasado también les sirvió para enarbolar la soberanía de los Estados en el ámbito de las relaciones internacionales. Así, en un segundo apartado, se propone una reivindicación del republicanismo como discurso político útil para posicionarse críticamente frente a la dominación externa que padecen, sobre todo, Estados periféricos como los latinoamericanos debido a las condicionalidades impuestas por organismos financieros internacionales, empresas multinacionales y Estados hegemónicos en el marco del proceso de globalización neoliberal de las últimas décadas.

Abstract: The neo-republicanism of Quentin Skinner, Philip Pettit and Maurizio Viroli has the merit of having recovered the republican idea of freedom to critically approach the different forms of domination that permeate contemporary democratic societies. However, in the first section, it is argued that such normative proposals make insufficient use of the critical reaches of republican freedom, because they only instrumentalize it to defend the freedoms of individuals, despite the fact that it also served the republicans of the past to raise the sovereignty of States in the field of international relations. Thus, in a second section, a vindication of republicanism is proposed as a useful political discourse to critically position itself in the face of the external domination suffered, above all, by peripheral states such as those in Latin America due to the 
conditionalities imposed by international financial organizations, multinational companies and hegemonic states in the framework of the neoliberal globalization process of the last decades.

\section{l. Introducción}

Desde las décadas de los setenta y ochenta, el interés por el republicanismo aumentó considerablemente en el ámbito académico, habiendo sido bastante determinante para ello la publicación de El momento maquiavélico de John Pocock. Allí, se sostuvo que el republicanismo representa un "patrón de pensamiento político e histórico" (2016: 83) de profundas raíces greco-latinas, cuyo influjo fue decisivo en el contexto político italiano, más tarde en el inglés y escocés y, finalmente, en el norteamericano. Ahora bien, ¿cuáles han sido las consignas enarboladas por esta tradición política? Según Pocock, escritores como Cicerón, Maquiavelo, Milton y Rousseau coincidieron en su crítica de los poderes arbitrarios encarnados en tiranos y oligarcas, en su promoción del bien común y de la virtud cívica, en su afán por establecer un gobierno fundado en leyes y en su defensa de la soberanía de la patria frente a enemigos externos.

Este redescubrimiento de Pocock y otros historiadores ${ }^{1}$ generó que una serie de es-

1. Como recuerda Tudela-Fournet (2015), otros dos escritos fueron fundamentales para que el republicanismo se posicionase como un objeto de estudio destacado en el ámbito académico: Los orígenes ideológicos de la Revolución Americana (1967) de Bernard Bailyn y La creación de la república americana (1969) de Gordon Wood. En el primero, el argumento central es que, en los panfletos publicados en las colonias británicas hacia finales del siglo XVIII, no es posible reconocer un discurso ideológico critores encontrasen en los valores republicanos una inspiración para concebir un modelo de democracia distinto del liberal. Tal es el caso de Quentin Skinner, Philip Pettit y Maurizio Viroli, quienes tienen en común el haber planteado que el republicanismo representa una teoría política cuyo valor central es la libertad entendida como ausencia de dominación. Una forma de comprender la vida libre desde la que puede enfocarse un sinfín de atentados contra las libertades individuales que acontecen en el contexto de las sociedades democráticas del presente, pero que no pueden ser visibilizados desde el hegemónico ideal liberal de libertad. Sucede que este último tiene como supuesto fundamental que la libertad solamente se encuentra afectada cuando el individuo padece interferencias explícitas y directas, mas no cuando está dominado por estar al arbitrio de otro individuo.

preminente. Ocurre que una importancia similar a la del discurso liberal la tienen otros discursos, entre los cuales destaca el republicano. Ahora bien, en el segundo escrito, Wood lleva más lejos las conclusiones de Bailyn, porque afirma que el republicanismo fue el discurso ideológico preminente en la época de marras. Y ello a pesar de que la tradición historiográfica angloparlante ha tendido durante largo tiempo a posicionar a John Locke como el padre intelectual de la Revolución Americana. No obstante, debe señalarse que, posteriormente, algunos historiadores han considerado exagerado este énfasis en el republicanismo como ideología preminente en el pensamiento y la acción de los revolucionarios americanos. Tal es el caso de Joyce Appleby (1992), para quien el redescubrimiento del republicanismo tiene su origen, ante todo, en el afán contemporáneo por encontrar alternativas teóricas y prácticas frente al liberalismo, el capitalismo y el marxismo con miras a desarrollar nuevos modos de ordenamiento legal, participación ciudadana y promoción del bien común. 
Debido a lo anterior, los neorrepublicanos piensan que la libertad enarbolada por liberales como Constant, Berlin, Rawls y Dworkin es inferior a la libertad republicana. Recuerda Viroli que, a diferencia de Berlin, ningún autor republicano denominó "libertad" a aquella condición que disfrutan los esclavos cuando viven bajo el poder de un déspota liberal, ya que, aunque aquellos no sufran ninguna interferencia, de todos modos, se encuentran siempre dependiendo de la voluntad de su amo, lo cual es suficiente para interpretar su existencia como dominada. Por eso, el liberalismo encarna un "republicanismo empobrecido, o incoherente, pero nunca una alternativa al republicanismo" (2014: 101). De hecho, cómo podrían ser abordados desde un liberalismo exclusivamente centrado en las interferencias contra los individuos el poder discrecional que tienen ciertas autoridades públicas frente a la ciudadanía, las amplias prerrogativas que poseen los empleadores con respecto a sus trabajadores en un ámbito laboral cada vez más desregulado o la facultad que todavía tienen muchos hombres de maltratar impunemente a las mujeres.

Pese a estas posibilidades que abre, el autor del presente artículo considera que el neorrepublicanismo no reivindica la libertad republicana de forma suficientemente audaz y crítica. Lo que sucede es que Skinner, Pettit y Viroli únicamente actualizan el republicanismo para enfrentar los distintos atentados contra las libertades individuales que acontecen dentro de la comunidad política. No obstante, los republicanos del pasado no se preocuparon solamente por la libertad de los ciudadanos frente a la presencia de tiranos y oligarcas, sino que también interpretaron como capital la libertad de los Estados frente a agentes externos con pretensiones imperialistas.
Como destacado continuador de una larga tradición republicana enfocada en la problemática de la dominación externa, puede mencionarse a Nicolás Maquiavelo, quien se preocupó por la débil posición geopolítica de las ciudades italianas frente a poderes como el de la Iglesia y el de España y Francia. Por eso, tanto en El Príncipe (2015) como en los Discursos (2012) propuso adoptar dos medidas fundamentales: la conformación de milicias ciudadanas capaces de luchar contra el enemigo externo por amor a la patria y la unificación de las ciudades italianas, pues manteniéndose estas divididas resultaría imposible la generación de contrapesos en el ámbito internacional. De manera semejante, Jean-Jacques Rousseau señala en El contrato social (2002) que una comunidad política puede ser esclavizada tanto por un agente interno como por uno externo. Y sobre este último tópico, destacan su crítica a aquellos intelectuales que defendían la existencia de un derecho a esclavizar a los pueblos (fundado en la enajenación voluntaria y en el triunfo de un rey conquistador) (138-148) y su convicción de que es infaliblemente mejor la comunidad que se basta a sí misma en los ámbitos políticos, económico y bélico (172).

Ciertamente, el asunto de la libertad de los Estados no generó gran interés en escritores republicanos ingleses del siglo XVII como Milton y Harrington. No obstante, como detalla el propio Skinner (2004), alcanzó un papel preponderante en el pensamiento inglés durante el siglo XVIII a través de defensores de la independencia de los colonos americanos como Richard Price, quien en Dos tratados sobre la libertad civil expresó que las colonias americanas eran estados esclavos en tanto que estaban sujetas a un cuerpo legis- 
lativo en donde no tenían voz ni control alguno. Por la misma época, mantuvieron vigente este enfoque republicano los autores norteamericanos de El Federalista (2014), los cuales reconocieron que la seguridad y la libertad de un pueblo pueden correr peligro por causas domésticas, pero también por las armas e influencia extranjera (9-10). Como principal medida para mantener la independencia de los Estados Unidos, recomendaron la configuración de un gobierno nacional bajo la forma de una república confederada, pues a través de esta podía alcanzarse un poder lo suficientemente amplio como para negociar con más ventaja con las potencias extranjeras (12-27)2.

Partiendo de estas consideraciones, el presente artículo se divide en dos secciones. En la primera, se demuestra que Skinner, Pettit y Viroli actualizan el republicanismo únicamente como teoría sobre la libertad individual, pese a que este también encarna una teoría sobre los Estados libres. Precisamente, en la segunda

2. Esta lista de escritores que se posicionaron críticamente frente a la dominación externa puede ampliarse con los representantes de la tradición republicana mexicana como Alonso de la Veracruz, Juan Zapata y Sandoval, Carlos de Siguenza y Gongora y Miguel Hidalgo (Velasco, 2009: 17-79). Ahora bien, desde el punto de vista del autor del presente artículo, también pueden ser incluidos escritores republicanos peruanos como Manuel Lorenzo de Vidaurre, José Faustino Sánchez Carrión y José Gregorio Paredes, quienes frente a la dominación española bajo la cual vivió el Perú, enarbolaron la soberanía nacional y la integración de Latinoamérica. Inclusive, habría que explorar hasta qué punto los enfoques de la filosofía de la liberación, la teoría de la dependencia y la teoría decolonial mantienen una línea de continuidad con dicha tradición republicana latinoamericana en tanto que todas ellas comparten la profunda preocupación frente a la dominación de origen externo. sección, se ensaya una reivindicación del republicanismo como alternativa teóricopolítica útil para configurar un posicionamiento crítico frente a los escenarios en los que resulta ser el Estado, y no el individuo, el sujeto político dominado. Así, se expone que dicho enfoque del republicanismo resulta conveniente para abordar, sobre todo, la dominación que padecen Estados periféricos como los latinoamericanos debido a la injerencia en los asuntos locales de Estados hegemónicos, organismos financieros internacionales y empresas multinacionales en el marco del proceso de globalización neoliberal.

\section{El neorrepublicanismo de Skinner, Pettit y Viroli: una revitalización del republicanismo como teoría sobre la libertad individual}

Como se sostuvo anteriormente, la propuesta normativa de Skinner, Pettit y Viroli se caracteriza por concebir el republicanismo como una teoría política cuyo valor central es la libertad entendida como ausencia de dominación. Ahora bien, tales neorrepublicanos coinciden en que la dominación de unos hombres sobre otros a la que se enfrentaron en su momento escritores como Maquiavelo, Cicerón y Rousseau también puede identificarse en las sociedades democráticas del presente. Así, se encuentra encarnada en

[...] el agravio expresado por la mujer que se halla en una situación tal, que su marido puede pegarle a su arbitrio, sin la menor posibilidad de cambiar las cosas; [en] el empleado que no osa levantar queja contra su patrono, y que es vulnerable a un amplio abanico de abusos, insignificantes unos, se- 
rios otros, que su patrono puede arbitrariamente perpetrar; [en] el deudor que tiene que depender de la gracia del prestamista, del banquero de turno, para escapar al desamparo manifiesto o a la ruina [...] (Pettit, 1999: 22)

Según Skinner (2004), es por ello fundamental recuperar el mundo intelectual asociado con el republicanismo como herramienta para visibilizar este tipo de atentados contra la libertad ${ }^{3}$. En una línea similar, Viroli refiere que hay que entender el significado del republicanismo en la historia con el fin de emplearlo en la constitución de una "nueva utopía política" para emprender una "lucha eficaz por la libertad" (2014: 41-57). Asimismo, Pettit (1999) expresa que la teoría republicana debe ser enarbolada como representativa de un ideal político esencial que requiere ser considerado en el debate de la filosofía política contemporánea para reflexionar ampliamente sobre el Estado, la virtud cívica y la libertad.

\footnotetext{
3. En una entrevista realizada por Bogers y Drejer (2016), Skinner aclara la relación entre sus labores de historiador y de filósofo normativo. Así, señala que el análisis histórico resulta crucial para desarrollar una propuesta político-normativa debido a que la vuelta al pasado puede ser útil en dos sentidos: 1) Para invocar ciertas tradiciones de pensamiento político con miras a reafirmar o refinar nuestros propios valores. Un ejemplo de lo anterior es la empresa intelectual de John Rawls, la cual consistió en reelaborar las teorías políticas de Locke y Kant. 2) Para encontrar alternativas ideológico-políticas que, por distintas razones, no han sido consideradas para fundamentar la teoría y la práctica políticas de nuestro tiempo. Precisamente, Skinner sostiene que esta última pretensión ha sido la suya al recuperar la tradición política republicana, pues desde ella pueden cuestionarse nuestras formas actuales de pensar sobre los derechos humanos y la libertad política bajo el prisma liberal.
}

Indudablemente, el ideal republicano de libertad resulta muy útil para enfrentar una serie de escenarios de injusticia, dominación y dependencia padecidos actualmente por individuos de distintas partes del mundo. Sobre todo, si se tiene en cuenta que tales atentados contra las libertades han sido insuficientemente atendidos por el liberalismo e incluso por otras corrientes ideológico-políticas como el comunitarismo ${ }^{4}$ y el democratismo. Sin embargo, el autor considera que Skinner, Pettit y Viroli desaprovecharon una interesante dimensión emancipadora de la libertad republicana debido a que actualizaron esta únicamente como una teoría acerca de las libertades individuales, pese a que los escritores del pasado también la concibieron como una teoría de los Estados libres.

Este rasgo característico del neorrepublicanismo se hace explícito, por ejemplo, cuando Skinner (2004) expresa que el republicanismo es importante, fundamentalmente, porque su concepción de

4. Aunque en el presente artículo se establece una diferenciación clara entre el republicanismo y el comunitarismo, debe señalarse que autores como Taylor (1994), Sandel (1996) y Honohan (2002) han recuperado la tradición política republicana en clave, precisamente, comunitarista. De esta forma, a diferencia de Skinner, Pettit y Viroli, han atribuido a los escritores republicanos clásicos la defensa de un ideal positivo de la libertad. A partir de ello, tales autores han reivindicado un republicanismo en el marco del cual el autogobierno, la libertad y la autorrealización de los individuos se alcanzaría a través de la identificación de estos con un proyecto común, con una matriz de tradiciones y con un conjunto de valores morales. Una base esta última sobre la base de la cual también sería posible la configuración de la integración de los miembros de un colectivo con miras a la defensa de la soberanía popular, es decir, del autogobierno en un sentido más amplio. 
la libertad como ausencia de dominación pone en tela de juicio la tesis liberal según la cual un individuo es libre solo cuando no padece interferencias abiertas y directas. Un profundo cuestionamiento que, a su vez, coloca las bases para un abordaje crítico del papel de los Estados democrático-liberales, dado que estos siempre se han limitado a buscar que nadie interfiera ni injusta ni innecesariamente en la vida de los individuos. No obstante, en opinión de Skinner, todo aparato estatal también debiera tener como objetivos garantizar que "sus ciudadanos no caerán en una situación de dependencia de la buena voluntad de otros [y] evitar que sus propios representantes, investidos con un poco de autoridad, se comporten en forma arbitraria al imponer reglas que rigen la vida común" (2004: 75).

De manera similar, el neorrepublicanismo de Pettit se restringe a recuperar la libertad republicana para visibilizar la dominación que los individuos padecen en el marco de las sociedades actuales. Así, en el prefacio de Republicanismo, recuerda que las ideas de Cicerón, Maquiavelo y otros escritores captaron su atención porque le sirvieron para entender los distintos ángulos de las arbitrariedades que él mismo sufrió como individuo dentro de ciertas organizaciones religiosas a las que perteneció. Según Pettit, aunque estas brindaban una serie de beneficios, jamás enseñaron a sus miembros a mirar de frente a las autoridades, sin temor a posibles represalias. Por el contrario, tales instituciones comunicaban a los individuos "un sentido de vulnerabilidad y exposición sistemáticas al arbitrio de la autoridad, haciendo a veces incluso virtud de esa práctica" (1999: 12).

En consonancia con lo anterior, Pettit expresa claramente en la introducción de la obra citada que los liberales tendrían que sentirse atraídos por la tradición republicana debido a que, como la tradición liberal, también está "centrada en la capacidad individual de elección" (1999: 29), aunque teniendo la importante ventaja de poderle dar voz al "agravio del trabajador, o el de la mujer, o el del arrendatario, o el del deudor, quienes, dominados, aun sin sufrir interferencias reales, tienen sin embargo que fingir y adular y mirar con aprehensión a un amo que tiene poder [...] sobre ellos [...]" (1999: 176). Resulta evidente, entonces, que Pettit se concentra en recuperar el republicanismo como una teoría sobre la libertad individual frente a la dominación interna, olvidando que dicha doctrina política también brinda interesantes posibilidades críticas como una teoría sobre los Estados libres frente a la dominación externa.

Como se adelantó, Viroli coincide con esta actualización que Skinner y Pettit hacen de la libertad republicana, ya que siempre que en su Republicanismo y en otros escritos aborda la problemática de la dominación, se restringe a visibilizar escenarios en los que acontece que los sujetos políticos dominados son los individuos. Trae a colación, por ejemplo, la condición indigna en la que se encuentran los ciudadanos cuando su situación depende de la voluntad arbitraria de un tirano porque carecen de un orden legal e institucional que les proteja. También considera en reiteradas ocasiones tanto el caso de las mujeres que pueden sufrir maltratos por parte de sus maridos sin poder resistir ni obtener reparación (y viéndose obligadas a tener comportamientos serviles para evitarlos) como el de los trabajadores que están a discreción de sus empleadores, teniendo que sufrir por ello abusos y mezquindades (2014: 77-78). 
En el cuarto capítulo de Republicanismo, Viroli retoma su comprensión de la teoría política republicana como una herramienta útil para desentrañar el verdadero significado de la libertad individual. Allí, sostiene que las leyes e instituciones desarrolladas en el marco de una sociedad republicana traerían como consecuencia que haya

cada vez más mujeres y más hombres que no dependan del juicio arbitrario de los demás para emprender una carrera tanto en el sector público como en el privado; [...] cada vez menos ciudadanos que se sientan indefensos frente a la autoridad pública y a la burocracia; [...] cada vez menos ciudadanos obligados al silencio y a la pasividad, porque se suele considerar inferior su grupo social, cultural o étnico, así como de poco valor su historia; [...] cada vez menos ciudadanos discriminados o tratados con arrogancia o suficiencia en el puesto de trabajo, o que están marginados, o automarginados, en el interior de la vida doméstica. (2014: 102)

Un importante detalle a considerar es que, a diferencia de Skinner y Pettit, Viroli concibe su propuesta normativa como un patriotismo republicano, ya que le resulta capital el fomento del amor hacia la patria para movilizar a los ciudadanos de nuestro tiempo en favor de la libertad, la igualdad y la justicia. De esta manera, tal y como él mismo aclara, no hace más que emular a los escritores republicanos del pasado, para quienes el patriotismo representaba la principal pasión que fortalece la virtud cívica. Ahora bien, no cabe duda de que esta dimensión patriótica de su republicanismo puede llevarnos a pensar que Viroli sí se preocupó por abordar aquellos escenarios del presente en los cuales es el Estado el sujeto dominado desde el exterior. No obstante, el amor por la patria que reivindica es un tipo de amor que encuentra su expresión en la defensa que, para él, deben hacer los ciudadanos de sus libertades frente a los déspotas. De ahí que en Por amor a la patria (2019) señale a los tiranos y corruptos (esto es, a agentes que operan dentro de las fronteras de la comunidad política) como los enemigos por antonomasia de la patria, pues sus acciones suelen estar encaminadas hacia la consecución de sus fines particulares en desmedro del bien común $^{5}$. Entonces, aunque Viroli tiene el mérito de haber revitalizado la dimensión patriótica de la tradición republicana, la misma no le lleva a posicionarse críticamente frente a la dominación externa que todavía en nuestro tiempo padecen Estados periféricos como los latinoamericanos.

Un aspecto que llama la atención es que cuando Skinner, Pettit y Viroli exploran, desde un punto de vista histórico, los valores y consignas del republicanismo, señalan de manera enfática que sus representantes entendieron que la libertad posee dos dimensiones: ausencia de dominación interna y ausencia de dominación externa. En La libertad antes del liberalismo, Skinner recuerda que la forma de entender la libertad individual por parte de los escritores republicanos tiene como origen su concepción de lo que representa ser un Estado libre. Por ende, reconoce él mismo que aquellos "no comienzan centrándose en la libertad de

5. En una entrevista realizada por Del Palacio (2019) a Viroli a propósito de la reciente publicación de su libro Por amor a la patria, este afirma que la tiranía y la corrupción se encuentran encarnadas actualmente en políticos de derecha defensores de un populismo nacionalista contrario al pluralismo cultural y la inmigración. Con ello, vuelve a explicitarse que al autor italiano recupera el republicanismo, ante todo, como una teoría sobre la libertad individual. 
los individuos, sino en lo que Milton denomina la 'libertad común' o el 'gobierno libre', lo que Harrington Ilama 'la libertad de una commonwealth', y lo que Sidney llamó después 'las libertades de las naciones' [...]" (2004: 24-26). En ese sentido, un individuo es libre cuando, como un Estado libre, es "capaz de actuar según su propia voluntad, en pos de sus propios fines" (2004: 103-104). O, siguiendo las palabras de Pettit, puede decirse que en la tradición republicana "las condiciones en las que un ciudadano es libre son las mismas en las que la ciudad o el estado es libre" (1999: 58). Quiere decir que los republicanos coincidieron al utilizar el término libertad "en el sentido de ser libres de toda intervención externa, así como en el sentido de ser libres de tomar parte activa en la administración de su comunidad" (Los fundamentos 95). Y, por esa razón, afirma Viroli que fueron plenamente conscientes de que toda república "debe protegerse de los agresores externos que quieren quitarle la independencia, así como de los arrogantes que quieren imponer su propia voluntad por encima de las leyes y convertir, de esa manera, a los ciudadanos en súbditos" (2014: 54-55). No obstante, cuando Skinner, Pettit y Viroli dejan de lado el análisis histórico para desarrollar su propuesta normativa, simplemente renuncian a cualquier tipo de valoración de la libertad como ausencia de dominación externa.

Ciertamente, en unos pocos pasajes de sus principales escritos, tales autores exponen algunos planteamientos acerca del rol que deben desempeñar los Estados en el ámbito internacional. El importante detalle a tener presente es que este abordaje se encuentra lejos de aprovechar los alcances críticos del republicanismo para enfrentar la dominación externa. Así, fren- te a la posibilidad de que un país domine a otro, señala Pettit que lo mejor es que aquel que corra peligro haga todo lo posible por no emprender ni una carrera armamentísitica ni un ataque preventivo, pues tienen que aspirar a ser "un buen ciudadano internacional" (1999: 201). Según él, una opción verdaderamente viable y eficaz es que los Estados busquen garantizar la ausencia de dominación externa por medio de la configuración y fortalecimiento de un orden internacional dirigido por instancias supranacionales. Sucede que las redes culturales, económicas y jurídicas tanto regionales como globales disciplinan a sus miembros, por lo que resultaría conveniente para cualquier Estado brindar su apoyo a un organismo como las Naciones Unidas, "en la medida en que promete ser capaz de contener los conflictos, y eventualmente, hacerlos más y más improbables" (1999: 200). Un punto de vista asumido también por Viroli, para quien es crucial la existencia de instituciones supranacionales con miras a que se castiguen distintos tipos de delito, aunque siempre en coordinación con las instituciones políticas nacionales y en el marco de los límites jurídicos. En el caso particular de Europa, detalla, esto puede ser bastante útil para que los países que la conforman otorguen forma a "una política común para la paz y la seguridad, que se proponga proteger los ciudadanos europeos no solo de los ataques externos, sino también del terrorismo y de la criminalidad organizada" (2014: 143-144).

Para el autor del presente artículo, estos planteamientos de Pettit y Viroli para hacerle frente a la dominación externa pueden ser cuestionados en dos sentidos. En primer lugar, una importante deficiencia de dicho análisis es que parece tener como punto de partida el supuesto de que 
la invasión militar y la posibilidad de concretarse de esta en cualquier momento representan las únicas dos formas en que un Estado puede padecer dominación en la actualidad. Pero, zacaso en el marco del proceso de globalización neoliberal no es patente que un Estado puede ejercer dominio sobre otro sin necesidad de emplear medios militares? Por otro lado, ¿no resulta equivocado pensar en la dominación como un fenómeno que acontece exclusivamente entre Estados? En segundo lugar, puede cuestionarse que Pettit y Viroli interpreten el papel de las instituciones intergubernamentales de forma tan acrítica y optimista, pues tienden a concebirlas como árbitros imparciales y objetivos. Sin embargo, ¿no acontece en un sinfín de ocasiones que tales instancias globales se comportan como agentes dominantes, sobre todo, frente a Estados periféricos? A propósito, llama la atención que, para Pettit, no tiene que alarmar que organismos internacionales reduzcan la soberanía de los Estados, porque "no hay nada sagrado desde el punto de vista republicano, en el estado mismo o en la soberanía estatal" (1999: 201). Sin embargo, tal y como se ha sostenido antes, en la tradición republicana la independencia del Estado no es un asunto más, sino que encarna una de las dos dimensiones de la libertad, por lo que es difícil admitir que autores como Cicerón, Maquiavelo y Rousseau no habrían tenido un posicionamiento crítico frente a las condicionalidades que padecen los Estados de la periferia en el actual orden internacional.

Cabe destacar que, aunque en sus principales escritos Skinner también se limita a reivindicar el republicanismo como una teoría sobre la libertad individual, en una entrevista sugiere que es posible aprovechar la libertad como ausencia de do- minación para visibilizar el sometimiento que ejercen los países desarrollados sobre los subdesarrollados. Lo cual le lleva a sostener que una demanda moral central que se deriva de la libertad que a él le interesa es "que la comunidad internacional minimice estas relaciones de dominio y dependencia y busque un mundo más equitativo" (Quijano, Francisco y Giannakopoulos, Georgios, 2013: 167-191). En otro momento, Skinner inclusive se aventura a presentar a las empresas multinacionales como agentes dominantes, ya que suelen imponer las condiciones de inversión y de empleo, "y tienen el poder de amenazar con el retiro de su inversión de los Estados locales con la correspondiente eliminación de fuentes de empleo, si sus demandas no son satisfechas, aun cuando esas demandas son contrarias a las prioridades de los Estados" (Quijano, Francisco y Giannakopoulos, Georgios, 2013: 167-191). En suma, pese a que dicho autor no llega a revitalizar el republicanismo como una teoría sobre los Estados libres, por lo menos deja en esta referencia breve y aislada algunas pistas en torno a la utilidad que puede tener aquel en tal sentido.

Pero, ia qué se debe que los neorrepublicanos se hayan limitado a recuperar el republicanismo como una teoría sobre la libertad individual? Para el autor del presente artículo, la polémica con el liberalismo en la que se enfrascan Skinner, Pettit y Viroli es una de las razones principales. Entrampados, pues, dentro de los límites trazados por una tradición liberal siempre centrada en la temática de los derechos y libertades individuales y tangencialmente preocupada por tópicos como el imperialismo y las relaciones de dependencia entre naciones, los tres neorrepublicanos no reparan en la posibilidad de actualizar 
la libertad republicana como soberanía o independencia del Estado. Puede decirse que el principal objetivo de ellos no es poner en tela de juicio el fondo de la doctrina liberal, ya que también enarbolan enfáticamente el principio de que los individuos pueden encontrar la felicidad, el bienestar y la autorrealización a través de formas de vida diferentes entre sí. Así, la descripción que hace Tudela-Fournet (2015) acerca del neorrepublicanismo de Skinner resulta útil también para describir aquel que enarbolaron Pettit y Viroli, pues los tres se concentraron en dar cuenta de cómo es que la libertad negativa asociada con el liberalismo es insuficientemente audaz y compleja para visibilizar una serie de atentados contra las libertades individuales y en formular la pregunta sobre si los liberales contemporáneos como Rawls tienen necesariamente razón al señalar que la mejor forma de garantizar y maximizar el valor de la libertad es tratar las obligaciones sociales como interferencias injustificadas.

\section{La libertad republicana como ausencia de dominación externa: una actualización en el marco del proceso de globalización neoliberal}

Entonces, la dimensión de la libertad republicana desde la que puede visibilizarse la dominación externa no es aprovechada por las propuestas normativas de Skinner, Pettit y Viroli. Una dimensión emancipadora que posee actualmente especial relevancia debido a que de un tiempo a esta parte Estados periféricos como los latinoamericanos han perdido importantes cuo- tas de autoridad y poder sobre los asuntos locales ${ }^{6}$. Pero, ¿exactamente por qué esta crisis de soberanía estatal está vinculada con aquella dominación de origen exterior abordada críticamente por los republicanos del pasado?

En primera instancia, debe señalarse que esta pérdida de poder de los Estados es una consecuencia del proceso de globalización neoliberal en el marco del cual se desarrolla la mayoría de sociedades democráticas. Por un lado, al generar la globalización una profunda interdependencia económica, trajo consigo el

6. Cabe destacar que una recuperación del republicanismo en el sentido propuesto por el autor del presente artículo, se sugiere brevemente en la introducción de Nuevas ideas republicanas: Autogobierno y libertad (2004). Allí, Ovejero, Martí y Gargarella traen a colación el hecho de que, en las democracias liberales contemporáneas, las decisiones más elementales sobre la organización de nuestras vidas no están bajo nuestro poder. Así, es patente, desde su punto de vista, que grandes masas de población «pueden ver cómo sus condiciones de vida cambian de la noche a la mañana no como resultado de sus decisiones, de sus esfuerzos o de sus errores, sino de flujos financieros o de poderosas voluntades especuladoras, hasta el punto de que las propias instituciones políticas no actúan en respuesta a las demandas de sus ciudadanos, sino tratando de suministrar a los mercados "buenas señales" (y, con ello, el autogobierno se supedita a esas "fuerzas ciegas", entre otras cosas porque cualquier intento de ejercer un control sobre las propias condiciones de vida es interpretado como una "mala señal")» (12). De esta forma, tales autores actualizan la idea republicana de autogobierno como soberanía del Estado frente a los condicionamientos dominantes de agentes externos, no en el sentido de Taylor y Sandel, para quienes dicha idea debe asociarse necesariamente con la asunción por parte de un pueblo o comunidad de cierto horizonte cultural y moral como condición de posibilidad para la identificación y la autorrealización. 
condicionamiento de las políticas internas de las naciones, las cuales parecen conformar una gran aldea global (Cardona y Cardona, 2011). Así, al representar un corsé para un capitalismo que busca expandirse sin restricciones, una realidad política cerrada como la del Estadonación ha sido relativizada. Por otro lado, bajo la premisa de que la consecución de bienestar para los individuos requiere la configuración de un marco institucional que permita garantizar los derechos de propiedad privada, las fuentes de mercados libres y la libertad de comercio, el neoliberalismo ha conseguido que la mayoría de Estados renuncien a tener presencia en sectores relacionados con la protección social; lo cual ha dado paso a un sistema que coloca la responsabilidad individual por encima de todo y en el marco del cual se asume que problemáticas socio-económicas como la pobreza y el desempleo deben ser resueltas por la dinámica misma del mercado.

Si en el presente proceso de globalización neoliberal sobre todo los Estados periféricos han perdido el poder que antes ostentaban sobre una serie de áreas estratégicas, ¿qué instancias son las que han absorbido la administración de estas? Al perder su relación dialéctica con el poder, los representantes políticos tienden a descargarse de sus responsabilidades en favor de instancias globales como los Estados hegemónicos, los organismos financieros internacionales y las empresas multinacionales. Como manifiesta el sociólogo Zygmunt Bauman, "las condiciones en las que todos actuamos en estos tiempos fluyen en el espacio global, mientras que nuestras instituciones políticas siguen en general atadas al suelo" (2005: 133). Y en palabras del politólogo Juan Carlos Monedero, con cada asunción de instancias jurídicas supranacionales, acuerdos comerciales, decisiones de la OMC, el FMI o el Banco Mundial, de obligaciones señaladas por mecanismos internacionales de resolución de conflictos [...] el mantenimiento de una paridad económica, el derecho sobre las patentes, las calificaciones riesgo-país, la orientación comercial exterior, etc., los Estados nacionales estaban perdiendo estatalidad que iba a parar a Estados extranjeros o a manos privadas. (2009: 173-174)

Desde una perspectiva republicana, Io anterior implica que Estados como los latinoamericanos se encuentran al arbitrio de distintas instancias globales cuyo poder e influencia las asemeja a los agentes imperiales combatidos por escritores del pasado como Maquiavelo y Rousseau. Esto puede empezar a esclarecerse a través de un análisis del rol que cumplen en las naciones latinoamericanas las dos instituciones rectoras del proceso de globalización neoliberal: el FMI y el Banco Mundial. Ambas entidades tienen la función de gestionar la renegociación de las deudas que tienen dichos países con acreedores de origen internacional y de conceder a aquellos préstamos para que consigan estabilizar sus economías. Un importante detalle es que, a cambio, han venido exigiendo a tales países la aceptación de una serie de condiciones, las cuales consisten, por lo común, en ajustes estructurales tales como la reducción del gasto público, la flexibilización laboral, la privatización de sectores económicos estratégicos y la aceptación de acuerdos de libre comercio. Unas medidas que no han llevado a Latinoamérica y demás regiones del Tercer Mundo al prometido desarrollo, algo que se ha terminado de hacerse patente como consecuencia de la pandemia por COVID-19. 
Considerando las consecuencias perniciosas de estos ajustes estructurales, cabría preguntarse, ¿cuál es la principal razón por la que los gobiernos de los países del Tercer Mundo insisten en pedir préstamos y programas de renegociación al FMI y demás organismos financieros internacionales? Ocurre que en los escenarios sumamente críticos por los que suelen atravesar tales países se hace tan necesario disponer de grandes cantidades de dinero para capear las crisis económicas que, por lo común, no queda otra opción que la de aceptar las condicionalidades de los organismos financieros internacionales. En ese sentido, las negociaciones entre estas instancias globales y los gobiernos tienen un carácter desigual, ya que el poder siempre está del lado de las primeras. Como señala Stiglitz, la evidente desproporción del poder entre el FMI y los países clientes "inevitablemente genera tensiones entre ambos, y la conducta del FMI en las negociaciones exacerba una ya de por sí difícil situación. Al dictar los términos de los acuerdos, ahoga cualquier discusión con el gobierno cliente -por no hablar del país en general- sobre políticas económicas alternativas" (2018: 185). En clave republicana, podría afirmarse que, como el prisionero de guerra que "decide" ser esclavo del vencedor para no terminar muerto, no son pocos los Estados que "deciden" acatar los ajustes estructurales para no sufrir una total desintegración de sus bases económicas. No obstante, en ninguno de los dos escenarios planteados los agentes están actuando con verdadera libertad.

Con miras a profundizar en la comprensión de este tipo de dominación externa, puede ser esclarecedor un testimonio de Stiglitz sobre la relación que tuvieron Corea del Sur y el FMI en los años noventa.
Según él, los economistas coreanos eran conscientes de que las políticas recomendadas por el FMI para su país serían desastrosas, pero se mantuvieron callados. Aunque él preguntó a los funcionarios del gobierno coreano el porqué de este mutismo, no obtuvo ninguna respuesta hasta una visita posterior que hizo a dicho país:

[...] los funcionarios coreanos, a regañadientes, me explicaron que temían disentir abiertamente. El FMI no solo podía haber interrumpido su propia financiación, sino que también podía haber utilizado su intimidante púlpito para desanimar las inversiones privadas [...] Al país, pues, no le quedaba elección [...] Un anuncio público por parte del FMI de una ruptura de las negociaciones, incluso un retraso en ellas, enviaría una señal sumamente negativa a los mercados. En el mejor de los casos, esta señal llevaría a una subida de los tipos de interés y, en el peor; a una interrupción completa de la financiación privada. Algo más grave para algunos de los países más pobres, que, en cualquier caso, tienen poco acceso a fondos privados, es que otros donantes (el Banco Mundial, la Unión Europea y muchos otros países) facilitan financiación solo con la aprobación del FMI (2018: 184-185).

Llegados a este punto, y volviendo sobre el enfoque republicano, estamos en condiciones de sostener que el FMI y demás organismos financieros internacionales pueden ser interpretados como agentes externos que ejercen dominación países como los latinoamericanos debido a que el gran poder que concentran 1) no hace posible una negociación en condiciones de libertad e igualdad en torno a los términos de los acuerdos y 2) genera una especie de temor en las instituciones y representantes políticos de distintas naciones. En efecto, para los escritores republicanos el solo exceso de poder de un agente 
frente a otro anula en este último toda posibilidad de actuar libremente, pues pasa a estar al arbitrio de aquel. Este fenómeno puede presentarse actualmente en las relaciones entre un gobernante y sus gobernados, entre un empleador y sus trabajadores, entre un hombre y una mujer (dominación interna), pero también, de acuerdo con lo defendido en este artículo, entre un organismo financiero internacional y un Estado (dominación externa). Asimismo, en la tradición republicana se señala que la dominación de un agente sobre otro produce efectos psicológicos como el miedo, el cual sumerge a los individuos en una forma de vida envilecida e indigna por las constantes actitudes serviles que reproducen. Por el miedo que padecen frente a la posibilidad de sufrir la voluntad arbitraria de gobernantes, empleadores y hombres, gobernados, trabajadores y mujeres suelen inclinarse por la hipocresía y la adulación. Al mismo tiempo, se ha visto que los Estados pertenecientes a la periferia (encarnados en unos representantes legítimamente elegidos por los ciudadanos) sienten miedo ante posibles decisiones arbitrarias del FMI y otras instancias globales, prefiriendo hundirse en el servilismo y la dependencia.

También el hecho de que tales organismos financieros internacionales no rindan cuentas a los pueblos subdesarrollados que afectan con sus medidas, es una buena razón para interpretarlos como agentes externos dominantes. Vale la pena recordar que, para los republicanos, toda entidad política que carezca de los mínimos controles y que no tenga que responder frente a nadie por sus acciones, se ubica en una posición despótica, a la manera del tirano que en el ámbito interno del cuerpo político se ubica más allá de toda ley. Como sugiere el econo- mista y ex presidente de Ecuador Rafael Correa, teniendo como respaldo la sumisión absoluta de una serie de gobiernos de turno, las burocracias del FMI, el Banco Mundial y el BID impusieron sus recetas neoliberales en distintas naciones del Tercer Mundo pasando por encima de los planes de gobierno presentados en campañas electorales y de los pronunciamientos de los pueblos en las urnas, "por lo que adicionalmente al fracaso económico y social, el neoliberalismo también lesionó gravemente la legitimidad del sistema democrático" (2014: 65-66). Como refiere Stiglitz, no son pocos los casos en los que tales acuerdos para reestructurar las deudas o para recibir préstamos incluso han establecido "qué leyes debía aprobar el Parlamento del país para cumplir con los requisitos u objetivos del FMI -y en qué plazo-" (2018: 185). De esta manera, una condicionalidad que se presenta como netamente económica, termina invadiendo ámbitos como el político y el social de las naciones.

Si bien este fluir de la estatalidad en el espacio global compromete también la soberanía de los Estados hegemónicos, la posición dominante de sus élites en distintas esferas he hecho que no se vean afectados seriamente por algunas de las más graves consecuencias del proceso de globalización neoliberal. Además, hay que tener en consideración que, en menor o mayor medida, tales países (de la mano con sus sectores comercial y financiero) son los que deciden qué deben hacer organismos financieros internacionales como el FMI y el Banco Mundial. La elección de los presidentes de estas entidades refleja, precisamente, quién tiene la sartén por el mango en la configuración del orden internacional actual, porque, aunque casi todas sus actividades tienen 
lugar en las naciones del Tercer Mundo, siempre están encabezadas por representantes de los países industrializados. Y nunca ha sido requisito indispensable que tales autoridades posean experiencia acerca del mundo en desarrollo (Stiglitz, 2018).

Además, debe resaltarse que, en el FMI, los Estados Unidos tienen la minoría de bloqueo de las decisiones frente a los demás países, mientras que, en el Consejo de Seguridad de Naciones Unidas, son las potencias con capacidad nuclear encabezadas por dicho país las que frenan o impulsan los distintos lineamientos. Por eso, tras la Segunda Guerra Mundial, es patente que los Estados Unidos se han posicionado como la potencia financiera hegemónica y como gendarme mundial único (Monedero, 2009). Otra prueba de esta posición de dominio que tienen los Estados hegemónicos en el tablero geopolítico mundial es el hecho de que las medidas económicas de orientación neoliberal cuya aplicación "recomiendan" a los países del Tercer Mundo, en un sinfín de ocasiones no son implementadas por ellos mismos. En efecto, aunque Estados Unidos y la Unión Europea recomiendan a tales países (a través del FMI, el Banco Mundial y otros organismos) que recorten los subsidios para el sector agrícola local y que eliminen la mayor cantidad posible de aranceles, mantienen medidas proteccionistas de este tipo para sus propias economías. Quiere decir que, gracias al enorme poder que tienen sobre aquellos organismos internacionales que podrían ponerles freno, los Estados hegemónicos se han posicionado, en gran medida, como sujetos políticos que se encuentran más allá de un sinnúmero de reglas y medidas fundadas en el proceso de globalización neoliberal. Por tanto, no cabe duda de que actúan de manera bastante similar a aquellos tiranos o déspotas que supieron perfilar los republicanos del pasado.

En este contexto marcado por la globalización neoliberal, también las empresas multinacionales se comportan como agentes que dominan desde el exterior a Estados no hegemónicos como los latinoamericanos. Sucede que, como manifiesta el mismo Skinner en una entrevista anteriormente comentada, las grandes corporaciones tienen el poder para establecer las condiciones de inversión y de empleo, al mismo tiempo que para amenazar con el retiro de su inversión de los Estados. Un tipo de relación desigual entre Estados y poder corporativo cuyo origen está en que este, en las últimas décadas, ha encontrado grandes facilidades para ampliar las fronteras de consumo y para adoptar una serie de métodos de acumulación de los que se ha derivado el surgimiento de monopolios y oligopolios en distintos sectores. En efecto, las inversiones extranjeras directas de orígenes estadounidense, chino, japonés y europeo han traído consigo que un número cada vez más reducido de empresas desterritorializadas y multinacionales alcance el dominio de los mercados. Por ello, no son excepcionales los casos en los que los ingresos anuales de los Estados periféricos son menores que los de aquellas. Como es evidente, esta diferencia de poder es, pues, uno de los principales motivos por los que una gran cantidad de Estados están obligados a cambiar sus marcos normativos para favorecer directamente los intereses del sector corporativo, aunque estos entren en conflicto con los intereses de los pueblos.

Ahora bien, debe considerarse que el poder corporativo trasnacional no solo ejerce su dominio rodeando la estatalidad para obtener ventajas y prerrogativas. También 
es posible que se incruste en aquellas instituciones públicas desde las que tendría que gestionarse, ante todo, el interés colectivo. Según Harvey, en la misma estructura estatal de los Estados Unidos se observa cómo "ejércitos de empleados al servicio de los grupos de presión corporativos (muchos de los cuales se aprovechan de la puerta giratoria entre el empleo estatal y el mucho más lucrativo empleo en las corporaciones) dictan efectivamente la legislación para que encaje con sus intereses específicos" (2005: 84). En ese sentido, puede afirmarse que actualmente la frontera entre el Estado y el poder corporativo resulta sumamente porosa; lo cual, si no ha dejado asfixiadas por completo las estructuras democráticas de las naciones, por lo menos las ha corrompido profundamente a partir del poderoso influjo del dinero ${ }^{7}$.

Volviendo a echar mano de las categorías del republicanismo, estamos en condiciones de sostener que sobre todo naciones periféricas como las latinoamericanas quedan al arbitrio o discreción de empresas multinacionales y desterritorializadas. Y, por esta razón, la soberanía de tales Estados queda lo suficientemente diezmada como para que les resulte bastante difícil organizar sus estructuras políticas y eco-

7. Prueba de ello es la naturaleza de los acuerdos comerciales que vienen impulsándose últimamente. Según Stiglitz, los aranceles en el mundo son sumamente bajos desde hace décadas. Por eso, la atención de los tratados se ha desplazado hacia la eliminación de las barreras no arancelarias " [...] y las más importantes de estas [...] son las normativas. Inmensas empresas multinacionales se quejan de que la incoherencia de las normativas encarece los negocios. Ahora bien, la mayoría de las normativas, pese a ser imperfectas, están ahí para algo: para proteger a los trabajadores, a los consumidores, a la economía y al medio ambiente" (2017: 296). nómicas con miras a garantizar el bienestar de la población. Algo que no podría ser de otra manera si se tiene presente que el poder corporativo se sirve de dos tipos de instrumentos para ejercer su dominio: o bien emplea medios sutiles y no interferentes como las amenazas, los chantajes y la producción de miedo vinculados con el papel de los medios masivos de comunicación y las calificadoras de riesgo-país o bien se sirven de medios abiertos, directos e interferentes como los lobbies, los retiros de inversiones y la incrustación en las instituciones públicas.

Llegados a este punto, es necesario enfatizar que esta dominación externa afecta directamente los intereses de los ciudadanos. Precisamente, esta es la razón por la que Skinner, Pettit y Viroli cometen un grave error al no haber comprendido que un sinnúmero de escenarios de dominación contra los individuos que visibilizan tienen su origen, en menor o mayor medida, en los condicionamientos impuestos desde el exterior por una serie de agentes. Por ejemplo, si muchos trabajadores de distintos sectores se encuentran al arbitrio de sus empleadores (siempre bajo la sombra del miedo a reprimendas, descuentos y despidos) se debe a la precarización de las condiciones laborales fomentada por instancias globales como el FMI y el Banco Mundial. De la misma manera, si los ciudadanos en su papel de clientes de un banco se encuentran a merced de las medidas unilaterales que pueda tomar este, se debe a la escasa regulación estatal sobre el sector privado también promovida por las instancias globales mencionadas. También podría referirse el caso de aquellos pacientes cuya salud depende únicamente de la buena voluntad de los médicos, porque esta fragilidad en la atención tiene una estrecha relación con la reduc- 
ción del gasto público que desde hace varias décadas viene impulsándose desde un enfoque neoliberal y que en el presente contexto de pandemia viene mostrando sus consecuencias más perniciosas.

\section{Conclusiones}

Finalmente, el presente artículo planteará algunas alternativas que pueden formularse desde el republicanismo para hacerle frente a la dominación externa padecida por los países latinoamericanos y del Tercer Mundo en general. En primera instancia, con miras a que sean verdaderos actores políticos frente a las distintas instancias globales que en la actualidad tienen enorme preponderancia, un nuevo republicanismo tiene que redefinir los alcances y límites de los Estados latinoamericanos en las relaciones internacionales. Un Estado mínimo y débil (básicamente legitimado por sus funciones jurídicas y policiales) no puede enfrentar los embates de los distintos agentes externos contra sus constituciones, leyes e instituciones. Resulta evidente, entonces, que los Estados latinoamericanos deben ser refundados para que dejen de ser meros entes espectadores y vuelvan a ser reguladores y fiscalizadores. Sin embargo, esta reivindicación que se está planteando de la soberanía de los Estados periféricos no debe interpretarse como una invocación de un nacionalismo de fronteras cerradas como el que una serie de gobiernos de derecha vienen enarbolando en las últimas décadas. De hecho, los vínculos cada vez más estrechos entre los distintos países pueden representar una oportunidad para enfrentar con eficacia una serie de problemáticas sociales, políticas y económicas que tienen una dimensión mundial, tales como el narcotráfico, el calentamiento global y las pandemias. Además, el fortísimo impulso que tiene la integración mundial hace pensar que el proceso globalizador representa un fenómeno irreversible, del cual tienen que aprovecharse sus ventajas y contrarrestarse sus desventajas dentro de los límites de lo posible.

El importante detalle a considerar es que este proceso de integración de las naciones no tiene por qué suponer una renuncia de los Estados latinoamericanos a una serie de competencias y facultades sobre áreas estratégicas de vital importancia para los intereses colectivos. Así, la crisis financiera internacional del 2008 y la crisis presente por el COVID-19 han terminado de manifestar que carece de sentido insistir con una globalización concebida como proceso autónomo y autopoiético radicalmente desvinculado de las distintas problemáticas por las que atraviesan las naciones. En ese sentido, la referida refundación de los alcances y límites de los Estados desde el republicanismo tendría que traer consigo, puntualmente, que se constituya a estos como agentes con una participación más activa en la regulación de los flujos de dinero en el sistema financiero internacional y con una intervención más amplia en la configuración de mecanismos de provisión social para los menos favorecidos. Ocurre que, si el Estado no establece reglas claras y deja a su libre albedrío al mercado, acontecerán grandes quebrantos "ante la irresponsabilidad con la que se dan los préstamos, se conducen las empresas y solo se da prioridad a la ganancia inmediata sin pensar en los efectos sobre la economía a largo plazo" (González, 2010: 94). No puede solamente pensarse en la necesidad de crear un mercado mundial como el impulsado por la globalización neoliberal, sino 
que es indispensable la creación de una sociedad global. En palabras de Rafael Correa, debe buscarse la realización de "sociedades nacionales y globales con mercado, gobernando al mercado para alcanzar los objetivos socialmente deseables, y no sociedades de mercado, donde sociedades, vidas y personas estén sometidas a la entelequia del mercado" (2014: 152).

Entonces, frente a los distintos escenarios de dominación externa que padecen, los gobiernos latinoamericanos deben emprender la lucha por una globalización contrahegemónica desde la que sea posible la afirmación de importantes márgenes de soberanía para los Estados, pero también la articulación de formas alternativas de integración regional para nuestras naciones (Monedero, 2009: 109). Dos valores políticos estos últimos que se encuentran en el centro de la teoría republicana, pues, como se señaló anteriormente, Cicerón, Maquiavelo, Rousseau, entre otros, estuvieron convencidos de que la realización de ambos es clave para generar los contrapesos frente a los poderes externos dominantes.

De hecho, unos países latinoamericanos poseedores de unos niveles básicos de soberanía e integrados entre sí podrían exigir que los organismos financieros internacionales y los Estados hegemónicos consideren sus demandas y condiciones al momento de configurarse las estrategias de desarrollo y financiamiento de escala mundial. Además, la afirmación republicana de tales valores políticos también generaría un contrapeso frente al poder cada vez más amplio de las empresas transnacionales; de esta manera, podría negociarse con estas convenientemente las condiciones de inversión y empleo en las naciones y se haría posible combatir (siempre a través de mecanismos legales e institucionales) la evasión de impuestos, la configuración de monopolios y las puertas giratorias Estado-empresas ${ }^{8}$.

Sin embargo, no cabe duda de que el republicanismo como teoría de la libertad frente a la dominación externa es un tópico todavía insuficientemente explorado, pese a que no solamente tiene raíces en la tradición republicana europea, sino también en la tradición republicana hispanoamericana9 ${ }^{9}$ Por eso, el presente artículo puede interpretarse como un primer intento del autor por ampliar los alcances críticos y emancipadores de la libertad republicana frente a una serie de escenarios de dominación que van más allá de los atentados directos contra las libertades individuales.

\section{Bibliografía}

Appleby, Joyce. (1992). Liberalism and Republicanism in the Historical Imagination. Cambridge-Mass, Harvard University Press.

8. En la presente pandemia, las enormes dificultades de los países latinoamericanos para adquirir vacunas tienen su origen, en gran medida, en la ausencia de una arquitectura supranacional desde la que pueda actuarse coordinadamente. Lo cual también ha producido que las multinacionales farmacéuticas hayan puesto condicionamientos bastante lesivos a nuestros países para proveerlos de dichos bienes. Contrariamente, aquellos países que han negociado en bloque (como los que conforman la Unión Europea y la Unión Africana) han logrado mejores resultados al respecto.

9. Al respecto, además del libro de Ambrosio Velasco (2009), puede resultar útil consultar Las repúblicas de aire. Utopía y desencanto en la Revolución de Hispanoamérica (2009) de Rafael Rojas. 
Bailyn, Bernard (1967). Ideological Origins of the American Revolution. Cambridge-Mass, The Belknap Press of Harvard University Press.

Bauman, Zygmunt. (2005). Amor líquido: Acerca de la fragilidad de los vínculos humanos. Buenos Aires, FCE.

Bobbio, Norberto y Viroli, Maurizio (2002). Diálogo en torno a la república. BarceIona: Kriterios Tusquets.

Bogers, Thijs y Drejer Bert. (2016). "Freedom as non-dependence. An interview with Quentin Skinner". Amsterdam Centre for Political Thought. Recuperado de http://www.acpt.nl/wp content/uploads/2016/03/ACPT-Freedom-as-nondependence-an-interview-with-Quentin Skinner-JUN2016.pdf. (Consulta: 20/01/2020)

Cardona, Hugo y Cardona, Porfirio. (2011). "El Estado-nación en la globalización y en el reordenamiento internacional." Revista Ciencias Estratégicas, 19. 25, 75-87.

Correa, Rafael. (2014). Ecuador: de Banana Republic a la No República. Medellín, DeBolsillo.

Del Palacio, Jorge. (2019). «Si existe alguna posibilidad de vencer al nacionalismo es redescubriendo el patriotismo». Entrevista a Maurizio Viroli. El Mundo. Recuperado de https://www.elmundo.es/cultura/201 9/02/11/5c60513afdddff3d628b4576. html. (Consulta: 14/01/2020)

González Ulloa, Pablo. (2010). "El Estado y la globalización ante la nueva crisis internacional." Política y cultura, 34, 89106.

Hamilton, Alexander, Madison, James y Jay, John. (2014). El Federalista. 2a. ed. México, FCE.
Harvey, David. (2005). Breve historia del neoliberalismo. Recuperado de: http:// ffyl1.uncu.edu.ar.

Honohan, Iseult. (2002). Civic Republicanism. Londres y Nueva York, Routledge.

Maquiavelo, Nicolás. (2012). Discursos sobre la primera década de Tito Livio. Madrid, Alianza editorial.

Maquiavelo, Nicolás. (2015). El príncipe. Madrid, Tecnos.

Monedero, Juan Carlos. (2009). Disfraces del Leviatán: El papel del Estado en la globalización neoliberal. Madrid, Akal.

Ovejero, Félix. Marti, José Luis y Gargarella, Roberto. (comp.) (2004). Nuevas ideas republicanas. Autogobierno y libertad. Barcelona, Paidós.

Pettit, Philip. (1999). Republicanismo: Una teoría sobre la libertad y el gobierno. Barcelona, Paidós.

Pocock, John. (2016). El momento maquiavélico: El pensamiento político florentino y la tradición republicana atlántica. 2a. ed. Madrid, Tecnos.

Quijano, Francisco y Giannakopoulos, Georgios. (2013). "Historia y política en perspectiva. Entrevista a Quentin Skinner." Signos Filosóficos, 15.29, 167-191.

Rojas, Rafael. (2009). Las repúblicas de aire. Utopía y desencanto en la Revolución de Hispanoamérica. México, Taurus.

Rousseau, Jean-Jacques. (2002). El Contrato Social. Trad. Consuelo Berges. Barcelona, RBA.

Sandel, Michael. (1996). Democracy's Discontent. London, Harvard University Press. 
Skinner, Quentin. (2004). La libertad antes del liberalismo. Madrid, Taurus.

Skinner, Quentin. (2013). Los fundamentos del pensamiento político moderno I. México, FCE.

Stiglitz, Joseph. (2017). La gran brecha. México, Penguin Random House.

Stiglitz, Joseph. (2018). El malestar en la globalización. 12a. ed. Barcelona, Penguin Random House.

Taylor, Charles. (1994). La ética de la autenticidad. Barcelona, Paidós.

Tudela-Fournet, Miguel. (2015). Crítica al neorrepublicanismo instrumental y su interpretación de la tradición republicana: Bien común frente a libertad como valor fundamental. (Tesis doctoral). Madrid, UAM.

Velasco, Ambrosio. (2009). La persistencia del humanismo republicano en la conformación de la nación y el Estado en México. México, UNAM.

Viroli, Maurizio. (2014). Republicanismo. Santander, Universidad de Cantabria.

Viroli, Maurizio. (2019). Por amor a la patria. Barcelona, Deusto.

Wood, Gordon. (1969). The Creation of the American Republic, 1776-1778. Chapel Hill, University of North Carolina. 
